\title{
Effect of chestnut tannin extract (Castanea sativa Miller) on the proliferation of Cladosporium cladosporioides on sheep cheese rind during the ripening
}

\author{
Anna Messini ${ }^{a}$, Arianna Buccioni ${ }^{a,}{ }^{*}$, Sara Minieri ${ }^{b}$, Federica Mannelli a , Laura Mugnai a \\ Cecilia Comparini ${ }^{a}$, Manuel Venturi ${ }^{\text {c }}$, Carlo Viti ${ }^{\text {a }}$, Antonio Pezzati ${ }^{a}$, Stefano Rapaccini ${ }^{\text {a }}$ \\ a Dipartimento di Scienze delle Produzioni Agro-Alimentari e dell'Ambiente, University of Florence, Piazzale delle Cascine 18, 50144 Firenze, Italy \\ ${ }^{\mathrm{b}}$ Dipartimento di Scienze Veterinarie, University of Pisa, Viale delle Piagge 2, 56124 Pisa, Italy \\ ${ }^{\mathrm{c}}$ Dipartimento di Gestione dei Sistemi Agrari, Alimentari e Forestali, University of Florence, Piazzale delle Cascine 18, 50144 Firenze, Italy
}

\section{A R T I C L E I N F O}

\section{Article history:}

Received 4 November 2015

Received in revised form

17 October 2016

Accepted 20 October 2016

Available online 14 November 2016

\begin{abstract}
A B S T R A C T
Strains belonging to the genus Cladosporium can cause black spots on the surface of sheep cheese, making it impossible to sell. Two water solutions of chestnut tannin extract (i) $200 \mathrm{~g} \mathrm{~L}^{-1}$ (CHE200) and (ii) $400 \mathrm{~g} \mathrm{~L}^{-1}$ (CHE400), and the chestnut tannin extract powder (CHEP) were tested in a cheese making trial in which 60 cheese units were allotted to 5 experimental groups (each of 12 cheeses: C1, control 1 without any treatment; $\mathrm{C} 2$, control 2 treated with a silver ion solution; and cheeses LCHE200, LCHE400, and LCHEP, treated with CHE200, CHE400, and CHEP, respectively). The cheeses were ripened in a room polluted with Cladosporium cladosporioides with the aim to create conditions for the proliferation of this fungus on the cheeses. The results indicated that chestnut tannin extract at a concentration of $200 \mathrm{~g} \mathrm{~L}^{-1}$ is capable of completely inhibiting C. cladosporioides proliferation, avoiding spoilage of the sheep cheese.
\end{abstract}

() 2016 Elsevier Ltd. All rights reserved.

\section{Introduction}

Cheese ripening is a complex process of biochemical changes involving several agents including endogenous milk enzymes, starter or non-starter microbiota, and secondary microorganisms such as moulds that can contaminate the cheese surface from the environment or can be purposely inoculated. For instance, in mould ripened cheeses, several starters such as Penicillium camemberti and Penicillium roqueforti, are inoculated specifically with the aim of improving the development of flavour and aroma by degrading proteins and lipids or fermenting sugars. Other moulds, such as Rhizomucor miehei, Rhizomucor pusilus, Cryphonectria parasitica, can be used to improve milk coagulation or accelerate the ripening of cheese (Cousin, 2003).

In contrast, moulds such as Mucor fuscus (forming black cottony spots), Thamnidium elegans (forming grey spots) and Cladosporium cladosporioides (forming black tight spots), or other potentially toxigenic species within the Penicillium, Aspergillus and Fusarium

\footnotetext{
* Corresponding author. Tel.: +39055 2755578.

E-mail address: arianna.buccioni@unifi.it (A. Buccioni).
}

genera, are very undesirable because their activity results in a deterioration of the aesthetical, nutritional and organoleptic qualities of cheese (Galli Volonterio, 2005; Kure, Wasteson, Brendehaug, \& Skaar, 2001; Montagna et al., 2004).

Colonisation by strains belonging to the genus Cladosporium is responsible for the damage to the surface of sheep and cow cheese, making it spotted and impossible to sell (Cousin, 2003; Delavenne et al., 2011; Gripon, 1993; Kure, Skaar, \& Brendehaug, 2004). It is not possible to remove this mould from the rind by wetting or drybrushing the cheese because it forms black unyielding and penetrating spots, formed by the fungal mycelium. Moreover, Cladosporium is one of the most common airborne moulds found in indoor and outdoor environments of dairy processing plants. Its spores are important aeroallergenes and the prolonged exposure to elevate spore concentrations can induce chronic allergy and asthma (Zeng, Westermark, RasmusonLestander, \& Wang, 2006). Also, the presence of this microorganism in cheese is not desirable from a consumer health perspective, being a potential risk of mycotoxin formation (Havaux, Zeine, Dits, \& Denis, 2005).

To avoid colonisation by strains belonging to the genus Cladosporium during the ripening, the surface of cheeses is normally 
covered with polymeric solutions enriched with antifungal agents such as Pimaricin or antimicrobial solutions containing silver ions. However, these approaches are discouraged because microorganisms can develop resistance and these substances are pollutants to the environment and problematic for their disposal.

Tannins are polyphenols and secondary metabolites, synthesised by plants against pathogens. These compounds are very heterogeneous and characterised by antimicrobial properties (Landete, 2011; Okuda, 2005). Chestnut wood from the Castanea sativa Miller plant species found across the entire Mediterranean area, contains hydrolysable tannins. Industries producing building materials use large quantities of wood that is chipped; if the wood is obtained from the chestnut tree, the chip (before its processing) can be steam distilled to obtain a hydrolysable chestnut tannin extract (CHE) characterised by a high level of pureness and high solubility (Romani, Campo, \& Pinelli, 2013). In the literature the antimicrobial properties of CHE are known; CHE is commonly used in the wine industry as a clarifying agent and colour stabiliser, and to bring body and flavour to wines lacking in taste and texture (Obreque-Slíer, Peña-Neira, López-Solís, Ramírez-Escudero, \& Zamora-Marín, 2009; Tosi et al., 2013).

The aim of this trial was to test the efficiency of CHE against C. cladosporioides proliferation on sheep cheese rind during ripening, as an alternative treatment to the use of antifungal agents or chemical solutions.

\section{Materials and methods}

\subsection{Isolation and identification of $\mathrm{C}$. cladosporioides from cheeses}

During the ripening (sheep cheese, produced by Caseificio il Forteto, Vicchio del Mugello, Firenze, Italy), 10 cheeses with black spots (Fig. 1A and B), formed by the fungal mycelium presumably belonging to $C$. cladosporioides, were placed in a separate sterile bag and immediately transferred to laboratory. In a sterile chamber, one of the spots from each cheese unit was isolated by streaking of the mould on to Petri dishes containing malt extract agar (MEA: code CM0059B; Oxoid s.p.a., Rodano, Italy). The dishes were incubated at $25^{\circ} \mathrm{C}$ for 7 days (Vaughan, Buzzini, \& Clementi, 2008; Wistreich, 1997). Based on morphology and colour of the colony and microscopic observation, thirty strains (three from each cheese unit) presumably identifiable as $C$. cladosporioides, were isolated as pure cultures.

For identification of the thirty strains, fungal colonies derived from single spores were cultivated on Potato Dextrose Agar (PDA; code P2182, Sigma-Aldrich, St. Louis, MO, USA). After 7 days of growth at $25{ }^{\circ} \mathrm{C}$ in the dark, mycelium (about $0.2 \mathrm{~g}$ of fresh weight) was harvested by scraping the surface with a scalpel. Genomic DNA was extracted from the mycelium using the DNeasy Plant Mini Kit (code 69104, Qiagen, Valencia, CA, USA) according to the manufacturer's instructions. The quality of genomic DNA was determined by electrophoresis on 1\% agarose gel (code 16500-500, Ultra Pure Agarose, Invitrogen, Carlsbad, CA, USA) and quantified using a spectrophotometer ND1000 Nano Drop (ThermoFisher Scientific, Wilmington, DE, USA). The internal transcribed spacer (ITS) region was amplified using the primers ITS1 ( $5^{\prime}$-TCC GTA GGT GAA CCT GCG G-3') and ITS4 (5'-TCC TCC GCTTAT TGA TAT GC- $\left.3^{\prime}\right)$ as described by White, Bruns, Lee, and Taylor (1990). Ten PCR products were purified with the QIA quick PCR purification Kit (code 28104, Qiagen) and stored at $-20{ }^{\circ} \mathrm{C}$ until used for sequencing. The sequence of the amplicons was performed by Eurofins Genomics Ebersberg, Germany. The sequence obtained in FASTA format were compared with those deposited in GenBank DNA database (http:// www.ncbi.nlm.nih.gov/) using the basicBLAST search tools (Altschul, Gish, Miller, Myers, \& Lipman, 1990).

\subsection{In vitro test on effect of $\mathrm{CHE}$ on the $\mathrm{C}$. cladosporioides growth}

Commercial CHE powder (CHEP) from chestnut wood extraction (Saviotan Feed $^{\circledR}$; provided by Gruppo Mauro Saviola, Mantova, Italy) containing $750 \mathrm{~g}$ of equivalent tannic acid $\mathrm{kg}^{-1}$ on dry matter (DM) basis was used for antimicrobial protection of the cheese rind. CHE extract was composed of only hydrolysable tannins and the gas-chromatographic profile is available in Campo, Pinelli, and Romani (2012). The tannic equivalents of the CHE extract were determined according to Burns (1963). Six water solutions of CHE were prepared at $35 \mathrm{~g} \mathrm{~L}^{-1}$ (CHE35), $50 \mathrm{~g} \mathrm{~L}^{-1}$ (CHE50), $75 \mathrm{~g} \mathrm{~L}^{-1}$ (CHE75), $100 \mathrm{~g} \mathrm{~L}^{-1}$ (CHE100), $200 \mathrm{~g} \mathrm{~L}^{-1}$ (CHE200) and $400 \mathrm{~g} \mathrm{~L}^{-1}$ (CHE400) of CHEP in sterile distilled water, mixing slowly to avoid foaming. All equipment was sterilised before the preparation of the solutions.

The in vitro antimicrobial ability of the different CHE solutions and of CHEP against $C$. cladosporioides was tested using the Kirby-Bauer antibiogram test (Bauer, Kirby, Sherris, \& Turck, 1966). An aliquot of the mould previously developed on the Petri dish (see Section 2.1) was distributed on $9 \mathrm{~cm}$ diameter Petri dish surfaces $(\mathrm{n}=40)$ containing MEA medium. Immediately, in the centre of each plates, a $10 \mathrm{~mm}$ diameter paper blotting diskette (Sigma-Aldrich), saturated with a CHE solution or CHEP or with sterile water as control (C) was positioned (8 plates per treatment). All plates were incubated at $25{ }^{\circ} \mathrm{C}$ for 7 days. Then, the different diameter halos of mould growth inhibition around the diskettes or the absence of inhibition zones were determined.
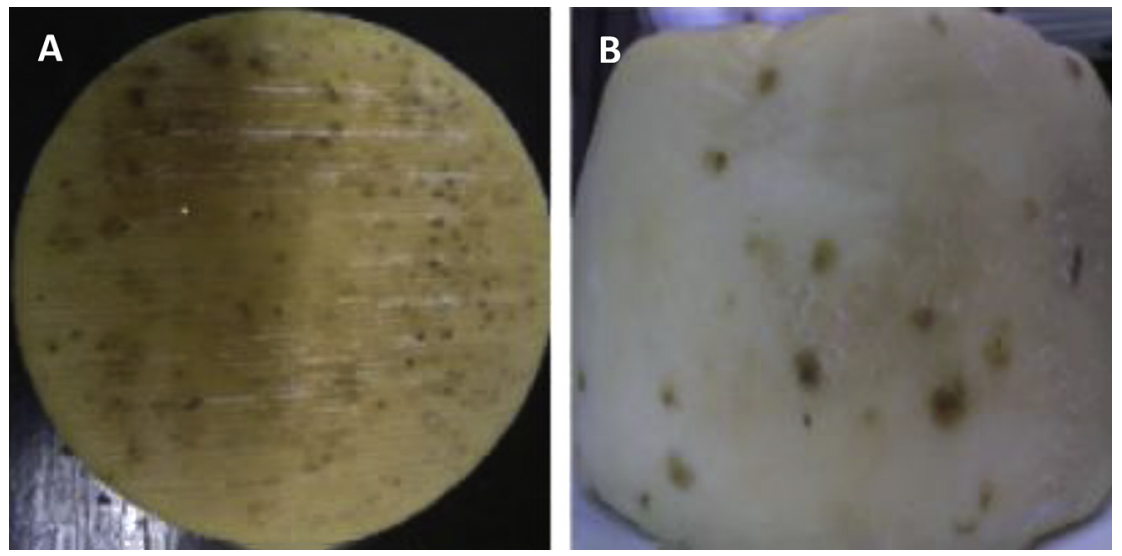

Fig. 1. Cheese with black spots formed by the fungal mycelium belonging to Cladosporium cladosporioides: A, top surface; B, lateral surface. 


\subsection{Cheese-making trial}

The cheese making was done at an industrial dairy processing plant located in Tuscany (Caseificio il Forteto, Vicchio del Mugello, Florence, Italy). The cheeses used for the experiment were produced using the same bulk milk, originating from 3 flocks of sheep.

The procedure of cheese making was as follows. After the pasteurisation process, the sheep milk was warmed to $35{ }^{\circ} \mathrm{C}$ and rennet (liquid animal rennet, code 25556, Danisco, Copenhagen, Denmark) was added to gel the milk ( $120 \mathrm{~mL}$ of rennet each quintal of milk corresponding to a rennet/milk ratio of $20 \mathrm{~mL}$ of rennet each quintal of milk; rennet strength 1:15000). Then, the milk was inoculated with a lyophilised starter culture that was composed of strains of Lactococcus lactis subsp. lactis and L. lactis subsp. cremoris (Lyofast CMS DOP 020, Sacco s.r.l., Italy; $0.05 \mathrm{~g}$ of lyophilised starter per each litre of milk). The final count of total starter bacteria was $10^{6} \mathrm{cfu}$ per litre of milk. After the milk clotting (30 min), the curd was cut to the size of a hazelnut and the vat temperature was kept at $35{ }^{\circ} \mathrm{C}$. Curds were placed into $2 \mathrm{~kg}$ moulds. Sixty-three cheeses were produced, and placed into a thermostatic chamber at $30^{\circ} \mathrm{C}$ for $6 \mathrm{~h}$ and turned five times. They were then held for a further $24 \mathrm{~h}$ at $20^{\circ} \mathrm{C}$, after which the cheeses were placed in a salt solution $(\mathrm{NaCl}$, $19 \%, \mathrm{w} / \mathrm{v}$ ) at $15^{\circ} \mathrm{C}$ for $24 \mathrm{~h}$ and finally transferred to a ripening room and analysed for mould and yeast (in triplicate).

The choice of the treatments was performed on the base of the in vitro trial results (see Section 2.2). After $5 \mathrm{~h}$ from salting, 60 cheeses were randomly allotted in 5 groups and treated as follows. For the first control cheese (untreated; C1), 12 units were not treated with any solution, and for the second control cheese (antimicrobial; C2), 12 units were treated with a commercial polymeric solution containing silver ions ( $250 \mathrm{mg} \mathrm{L}^{-1}$ AgPOLYMER $\mathrm{C}_{2}$, AgPolymer s.a.s, Torino, IT). To test CHE efficacy, 12 units were treated with CHE200 solution (LCHE200), 12 units were treated with CHE400 solution (LCHE400) and 12 units were treated directly with pure powder CHE (LCHEP). All solutions were applied by dipping the cheeses in the aqueous suspensions (60 s) while the powder was directly applied on the surface (until complete coverage of the surface; about $0.5 \mathrm{~mm}$ of thickness).

Twenty four 14-cm diameter Petri dishes containing C. cladosporioides, (strain Cc1; mycelium and spores; see Section 2.1), grown on MEA medium were placed (one open Petri dish per $\left.\mathrm{m}^{3}\right)$ in the ripening room $(3 \mathrm{~m} \times 2 \mathrm{~m} \times 4 \mathrm{~m})$ to contaminate the ventilated room with mould spores. The Petri dishes remained during the entire ripening period. A homogeneous spread of spores was achieved throughout the room by a ventilation system with an internal recycle of air.

After the rind treatment, the cheeses were ripened for 100 days at $11-12{ }^{\circ} \mathrm{C}$ and sampled at $15,40,80,100$ days from cheese making ( 3 cheeses at each time period per thesis) to monitor the fungal colonisation. On day 100, cheeses were analysed for proximate analysis, physical observation and fatty acid profile.

\subsection{Microbiological characterisation of cheeses}

At each sampling time, 3 cheeses were placed in to sterile bags and immediately transferred to the laboratory for the microbiological analysis. A one hundred square centimetre sterile silhouette was placed on the upper surface of each cheese (in the centre) and the designated area was scrubbed thoroughly with a cotton swab moistened with saline solution $\left(\mathrm{NaCl}, 9 \mathrm{~g} \mathrm{~L}^{-1}, \mathrm{w} / \mathrm{v}\right)$. The cotton swab was then reinserted into the tube containing $5 \mathrm{~mL}$ of the same solution $\left(\mathrm{NaCl}, 9 \mathrm{~g} \mathrm{~L}^{-1}, \mathrm{w} / \mathrm{v}\right)$, stirred and stored in the refrigerator until the determination of mould and yeast concentrations. Serial 10 -fold dilutions were then performed on the saline solutions and $100 \mu \mathrm{L}$ of each suspension were plated (5 replicates), using the spread plate method on MEA (Vaughan et al., 2008; Wistreich, 1997). Moulds and yeasts, recognisable by morphology and colour of colony and microscopic observation, were counted after incubation at $25{ }^{\circ} \mathrm{C}$ under aerobic conditions for 7 days and 3 days, respectively. To normalise the data distribution, the results were expressed as $\log _{10}$ of mean colonyforming units per $\mathrm{cm}^{2}$ ( $\mathrm{cfu} \mathrm{cm} \mathrm{cm}^{-2}$ ).

A representative number of mould and yeast colonies from MEA medium was randomly picked from different plates, purified and characterised by molecular methods to identify, at species level, the dominant microbial population. After a microscopic observation, 10 mould colonies and 10 yeast colonies from each treatment and from each sampling time were picked from the Petri plates; the isolates were 200 moulds and 200 yeasts.

Also, from samples $\mathrm{C} 1$ after 80 and 100 days of cheese ripening, 40 mould colonies having black colour were picked from the Petri plates.

\subsection{Identification of mould and yeast isolates}

Two hundred mould isolates, having white colonies, were identified and 20 were purified and sequenced as stated in Section 2.1. Similarly, 40 mould isolates having a black colour, were identified and 10 of them were purified and sequenced as stated in Section 2.1. The selecting criteria for the purification and sequencing of isolates were in accordance with Venturi, Guerrini, and Vincenzini (2012).

Two hundred yeast isolates were identified by PCR-RFLP analysis of the rDNA-ITS region as according to Granchi, Bosco, Messini, and Vincenzini (1999), using HaeIII, Hinfl and CfoI (Fermentas Inc, Burlington, ON, Canada) as restriction endonucleases. The restriction fragments were separated (at $100 \mathrm{~V}$ for $2.5 \mathrm{~h}$ ) on a $20 \mathrm{~g} \mathrm{~L}^{-1}$ (w/v) agarose gel (Lonza Group Ltd, Basel, Switzerland), containing ethidium bromide (Sigma-Aldrich) and TEB buffer (1 м Tris, 10 mм EDTA, 0.9 м boric acid, pH 8.3; Sigma-Aldrich). The profiles were observed by UV transillumination and compared with those reported in the literature (Esteve-Zarzoso, Belloch, Uruburu, \& Querol, 1999; Granchi et al., 1999; Pulvirenti, Solieri, Gullo De Vero, \& Giudici, 2004). To confirm the identification obtained by PCR-RFLP analysis of the rDNA-ITS region, PCR products of 20 representative strains were purified using Nucleo Spin Extract II (Macherey-Nagel GmbH \& Co. KG, Düren, Germany) and sent to BMR Genomics (Padua, Italy) for sequencing. The selecting criteria for the purification and sequencing of isolates were in accordance with Venturi et al. (2012). The sequences obtained in FASTA format were compared with those deposited in GenBank DNA database (http://www.ncbi. nlm.nih.gov/; Altschul et al., 1990).

\subsection{Chemical and physical characterisation of the cheeses}

Dry matter (DM) and crude protein (CP) were determined according to the 930.15 and 976.06 AOAC procedures (AOAC, 1995) while cheese fat content was analysed according to Gerber-Van Gulik (ISO/IDF, 1975). The thiobarbituric acid reactive substances (TBARS) method was adopted to monitor the oxidative status of cheese samples according to Patton and Kruiz (1951). Fatty acids from cheese samples were extracted and analysed for their profile according to published methods (Buccioni et al., 2010, 2012). All results for fatty acid composition are expressed as $\mathrm{mg} \mathrm{g}^{-1}$ of lipids.

Because tannins have the characteristic of colouring and of permeating the organic matter, each cheese unit was also evaluated for the colour of the crust and of the texture. 


\subsection{Statistical analysis}

The microbial data were checked for normal distribution by Shapiro-Wilk test (SAS, 1999) and normalised by $\log _{10}$ transformation. Hence, normalised data of microbial abundance were processed using a linear model with two fixed factor (treatment and time of ripening) and their interaction (SAS, 1999):

$\mathrm{y}_{\mathrm{ij}}=\mu+\mathrm{T}_{\mathrm{i}}+\mathrm{R}_{\mathrm{j}}+\left(\mathrm{Ti} \times \mathrm{R}_{\mathrm{j}}\right)+\mathrm{e}_{\mathrm{ij}}$

where $y_{i j}$ is the observation; $\mu$ is the overall mean; $T_{i}$ the treatment ( $i=1$ to 5 ), $R_{j}$ the time of ripening ( $j=1$ to 5 ), Ti $\times R_{j}$ their interaction and $\mathrm{e}_{\mathrm{ij}}$ the residual error. Multiple comparisons among means were performed using the Tukey's test.

Data of cheese chemical composition and fatty acid profile were analysed using the one way ANOVA (SAS, 1999).

\section{Results}

\subsection{Isolation and identification of $\mathrm{C}$. cladosporioides from cheeses}

All thirty isolates from the cheeses were identified by amplification of the ITS region and rITS amplicon size was 550 bp (Fig. 2); ten PCR products of the thirty were sequenced and their sequences matched those of C. cladosporioides in GenBank (EU030342) with $100 \%$ identity scores. Hence, all isolates were identified as C. cladosporioides (Fresen) G. A. de Vries. The molecular approach used for strain characterisation did not permit the identification of isolates at strain level. Therefore, since all the isolates showed a similarity with $100 \%$ identity scores, the selection was random and the strain Cc1 was chosen for in vitro tests.

\subsection{In vitro test on effect of CHE solutions and powder (CHEP) on the $\mathrm{C}$. cladosporioides growth}

The ability of the CHE solutions and powder to avoid the development of $C$. cladosporioides $C \mathrm{C} 1$ growth was evaluated using Kirby Bauer test (Fig. 3). CHE35 produced no inhibition on the C. cladosporioides mould growth. In contrast, all other solutions and the powder induced inhibition. The diameter of the inhibition halo increased with the concentration of CHE solutions: with CHE50 it was $15.0 \mathrm{~mm}$, while with CHE75 and CHE100 it was $20.0 \mathrm{~mm}$. In

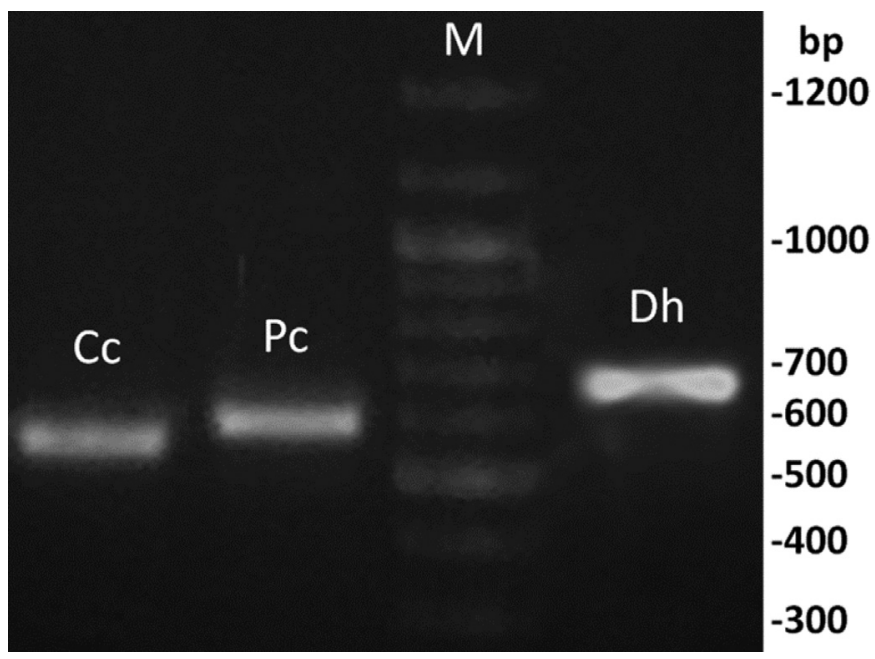

Fig. 2. Electrophoretic pattern of rITS-PCR products from Cladosporium cladosporioides (Cc), Penicillium commune (Pc) and Debaryomyces hansenii (Dh). M indicates the DNA molecular weight marker.

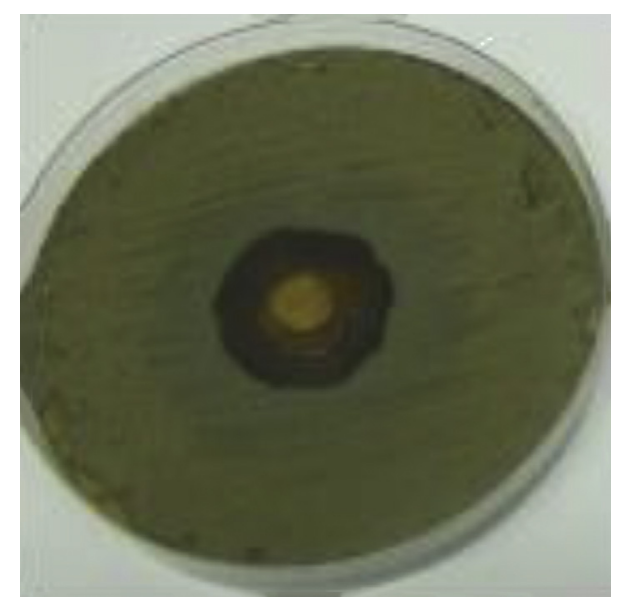

Fig. 3. Presence of inhibition halo surrounding the diskette.

particular, the greatest inhibition halo $(30 \mathrm{~mm})$ was produced by CHE200, CHE400 and the CHEP. Cc1 was used to contaminate the ripening room.

\subsection{Identification of moulds and yeasts in cheese rind}

During ripening moulds and yeasts proliferated on the cheese rind. Hence, the identification of these microorganisms was carried out. Two hundred mould isolates, presumably identifiable as Penicillium spp. base on microscopic observation and colony colour and morphology, were identified by amplification of the ITS region. The rITS amplicons were $580 \mathrm{bp}$ (Fig. 2). Twenty of the two hundred PCR products were sequenced and their sequences matched those of Penicillium commune in GenBank (DQ132814) with 99\% identity scores. Hence, all isolates were identified as P. commune (Thom).

Forty mould isolates, presumably identifiable as C. cladosporioides based on microscopic observation and colony colour and morphology, were identified by amplification of the ITS region. The rITS amplicons were $550 \mathrm{bp}$ (Fig. 2). Ten of the forty PCR products were sequenced and their sequences matched those of C. cladosporioides in GenBank (EU030342) with 100\% identity scores. Hence, all isolates were identified as C. cladosporioides (Fresen) G. A. de Vries.

All isolates of yeasts (total number 200), identified by amplification of the ITS region, were characterised by rITS amplicons having a size of $656 \mathrm{bp}$ (Fig. 2). To obtain species-specific PCR-RFLP patterns (Granchi et al., 1999), amplicons of all the isolates were digested with 3 restriction enzymes. The rITS restriction profiles were in base pairs: 400, 120, 75 for HaeIII; 315, 315 for Hinfl; 295, 280 for CfoI, suggesting the attribution of the isolates to the species Debaryomyces hansenii. ITS sequences of 20 strains, from 200, matched those of $D$. hansenii in GenBank (FR686595) with 100\% identity scores. Hence, all yeast isolates were identified as $D$. hansenii.

\subsection{Mould and yeast development on the cheeses surfaces during ripening of cheese}

The total number of moulds on cheeses before treatments was $1.9 \mathrm{cfu} \mathrm{cm}^{-2}\left(0.3 \log _{10}\right)$. At 15th day on LCHE400, moulds were lowest compared with those found on LCHE200, LCHEP, C1 and C2. Moreover, at this point of sampling the moulds detected on $\mathrm{C} 2$ were higher than those found in $\mathrm{C} 1$ and similar to those found on LCHE200.

At 15th day of ripening, total moulds on $\mathrm{C} 1$ cheeses had increased to $2.8 \times 10^{3} \mathrm{cfu} \mathrm{cm}^{-2}$ (3.5 $\left.\log _{10}\right)$; subsequently, they 
gradually increased about 10 times reaching the value about of $10^{6} \mathrm{cfu} \mathrm{cm}^{-2}\left(6.1 \log _{10}\right)$ at day 100 .

In LCHE400 and LCHEP, moulds increased to $10^{5} \mathrm{cfu} \mathrm{cm}^{-2}(4.9$ $\log _{10}$ ) on day 40 of ripening and this value remained almost unchanged until day 80. Total moulds detected on LCHE200 reached the maximum value at day 100 of ripening while C2, LCHE400 and LCHEP showed the lowest values, as exhibited in Table 1. A similar trend characterised the mould proliferation on C1 and LCHE200 during the whole period of ripening, reaching the highest value at day 100 compared with the other points of sampling.

Considering the fungal species, the most abundant was P. commune, present in all cheeses regardless of treatment on the rind and the time of sampling. In contrast, $C$. cladosporioides proliferated only on $\mathrm{C} 1$, reaching the number of $4.2 \times 10^{4} \mathrm{cfu} \mathrm{cm}^{-2}$ (4.6 $\left.\log _{10}\right)$ and $5.2 \times 10^{5} \mathrm{cfu} \mathrm{cm}^{-2}\left(5.7 \log _{10}\right)$, respectively, after 80 and 100 days of cheese ripening (Table 1 ).

The total number of yeasts on cheeses before treatments was $8.2 \times 10^{3} \mathrm{cfu} \mathrm{cm}^{-2}\left(3.1 \log _{10}\right)$. On C1 yeasts showed a fluctuating growth reaching the maximum value at day 100 while on C2 remained constant at all points of sampling with the exception of a decrease at day 40. The lowest value was found in LCHEP at day 15. Then, yeasts proliferated and the only differences were found respect to C1 at day 40 and day 80 . At day 100, C2 and LCHE200 were similar but higher than LCHE400 and LCHEP. In any case the values detected on all cheeses were very low during the whole period of ripening (Table 2).

Table 1

Total moulds in cheese rind during the ripening period. ${ }^{\mathrm{a}}$

\begin{tabular}{lllll}
\hline Cheese treatment & \multicolumn{4}{l}{ Time (days) } \\
\cline { 2 - 5 } & 15 & 40 & 80 & 100 \\
\hline C1 & $3.452^{\mathrm{Db}}$ & $4.270^{\mathrm{Cb}}$ & $5.110^{\mathrm{B}}$ & $6.072^{\mathrm{Ab}}$ \\
$\mathrm{C} 2$ & $5.107^{\mathrm{Ba}}$ & $5.410^{\mathrm{Aba}}$ & $5.716^{\mathrm{A}}$ & $4.974^{\mathrm{Bc}}$ \\
LCHE200 & $4.841^{\mathrm{Ca}}$ & $5.299^{\mathrm{Bca}}$ & $5.601^{\mathrm{B}}$ & $6.722^{\mathrm{Aa}}$ \\
LCHE400 & $2.185^{\mathrm{Cc}}$ & $5.390^{\mathrm{Aa}}$ & $5.539^{\mathrm{A}}$ & $4.708^{\mathrm{Bc}}$ \\
LCHEP & $2.945^{\mathrm{Cb}}$ & $5.237^{\mathrm{Aa}}$ & $5.628^{\mathrm{A}}$ & $4.542^{\mathrm{Bc}}$ \\
\hline
\end{tabular}

${ }^{a}$ Values (in $\log _{10} \mathrm{cfu} \mathrm{cm}^{-2}$ ) are means (standard error of the means was 0.263 ; number of samples for each treatment at any time $=3$ ); means with different uppercase and lower case superscript letters within a row and within a column, respectively, are significantly different $(P<0.05)$. Abbreviations are: $C 1$, control 1 (no treatment); $\mathrm{C} 2$, control 2 (treated with a commercial polymeric solution containing silver ion); LCHE200 and LCHE400, cheeses treated with the solution of chestnut tannin extract at $200 \mathrm{~g} \mathrm{~L}^{-1}$ and $400 \mathrm{~g} \mathrm{~L}^{-1}$, respectively; LCHEP, cheese loaves treated with chestnut tannin extract powder. In the case of $\mathrm{C} 1$, there was development of $C$. cladosporioides with $32 \%$ and $45 \%$ of the total moulds after 80 and 100 days, respectively, of cheese ripening; the probability of significant effect due to the interaction between experimental factors Treatment and Time was 0.0001 .

Table 2

Total yeasts in cheese rind during the ripening period.

\begin{tabular}{lllll}
\hline Cheese treatment & \multicolumn{4}{l}{ Time (days) } \\
\cline { 2 - 5 } & 15 & 40 & 80 & 100 \\
\hline C1 & $4.525^{\mathrm{Ba}}$ & $2.698^{\mathrm{D}}$ & $3.288^{\mathrm{Cb}}$ & $5.252^{\mathrm{Aa}}$ \\
$\mathrm{C} 2$ & $4.116^{\mathrm{Aa}}$ & $3.454^{\mathrm{B}}$ & $4.013^{\mathrm{Aa}}$ & $4.277^{\mathrm{Ab}}$ \\
LCHE200 & $2.954^{\mathrm{Bb}}$ & $2.954^{\mathrm{B}}$ & $3.954^{\mathrm{Aa}}$ & $3.854^{\mathrm{Ab}}$ \\
LCHE400 & $2.920^{\mathrm{Bb}}$ & $2.954^{\mathrm{B}}$ & $3.954^{\mathrm{Aa}}$ & $2.954^{\mathrm{Bc}}$ \\
LCHEP & $0.954^{\mathrm{Cc}}$ & $3.013^{\mathrm{B}}$ & $3.954^{\mathrm{Aa}}$ & $3.320^{\mathrm{Bc}}$ \\
\hline
\end{tabular}

\footnotetext{
${ }^{a}$ Values (in $\log _{10} \mathrm{cfu} \mathrm{cm}^{-2}$ ) are means (standard error of the means was 0.374 ; number of samples for each treatment at any time $=3$ ); means with different uppercase and lowercase superscript letters within a row and within a column, respectively, are significantly different $(P<0.05)$. Abbreviations are: $C 1$, control 1 (no treatment); $\mathrm{C} 2$, control 2 (treated with a commercial polymeric solution containing silver ion); LCHE200 and LCHE400, cheeses treated with the solution of chestnut tannin extract at $200 \mathrm{~g} \mathrm{~L}^{-1}$ and $400 \mathrm{~g} \mathrm{~L}^{-1}$, respectively; LCHEP, cheese loaves treated with chestnut tannin extract powder. The probability of significant effect due to the interaction between experimental factors Treatment and Time was 0.0002 .
}

\subsection{Proximate analysis, physical evolution and fatty acid profile}

The chemical composition of cheese and the oxidative status are reported in Table 3. No differences were found among cheeses with the exception of DM content that increased in LCHE400 and LCHEP. Moreover, the effect of treatments was not significant for fatty acid profile, which was similar among cheeses during the ripening period. For the sake of simplicity, this has been not reported in Table 3.

CHE coloured the rind but not the cheese itself, stopping at the surface and not diffusing in the cheese.

\section{Discussion}

CHE treatment did not modify the chemical features of the cheeses. Only CHE400 and the direct application of the powder (CHEP) seemed to increase water loss during ripening. The effect of treatment on the oxidative status of cheese was negligible, in accordance with a very low presence of oxygen inside the cheese matrix as consequence of good ageing conditions (Zottola \& Smith, 1993).

The proliferation of $C$. cladosporioides, which is able to grow at low oxygen level and to penetrate into the cheese, did not occur in any of the cheeses treated with $\mathrm{CHE}$, confirming the inhibition power of this extract previously tested in the in vitro experiment and used on the rind either in solution or directly as powder. This finding is in accordance with polyphenolic nature of CHE; in the literature the antimicrobial activity of this compound is well documented (Landete, 2011; Okuda, 2005; Tosi et al., 2013). Therefore, CHE treatment of the cheeses was useful in preventing an aesthetic damage due to black spots that compromise the marketing of cheeses and in avoiding the potential production of harmful mycotoxins (Cousin, 2003; Knutsen et al., 2012; Machado, Lozano, Bañón, Mojarrieta, \& Estevan, 2012; Sharpe, Bearman, Thornton, Husk, \& Osborne, 2015). Although improved sanitation and control of dairy plant air can contribute to a reduction in the level of mould spoilage of cheeses, $C$. cladosporioides is frequently found in several dairy products such as Jarlsberg or other Norwegian cheeses (Kure et al., 2004), French cheeses such as St. Nectaire and Tome de Savoie (Gripon, 1993) or even in cow milk and butter (Cousin, 2003; Delavenne et al., 2011) - being lipolytic, this mould produces off-flavours, including 2-methylisoborneol and geosmin that contribute to an undesirable earthy flavour (Sørhaug, 2011).

The identification of mould proliferated on the cheese samples showed that $P$. commune was the only mould present on the rind of treated cheeses. These data are in accordance with literature that

Table 3

Chemical composition and oxidative status of control and treated cheeses at day 100 of ripening. ${ }^{\text {a }}$

\begin{tabular}{llllllll}
\hline Parameter & \multicolumn{3}{l}{ Cheese } & & & SEM & $P$ \\
\cline { 2 - 6 } & C1 & C2 & LCHE200 & LCHE400 & LCHEP & & \\
\hline $\begin{array}{c}\text { DM }\left(\mathrm{mg} \mathrm{kg}^{-1}\right. \\
\quad \text { cheese) }\end{array}$ & $750.5^{\mathrm{c}}$ & $758.3^{\mathrm{c}}$ & $793.6^{\mathrm{b}}$ & $810.4^{\mathrm{a}}$ & $812.6^{\mathrm{a}}$ & 3.31 & 0.031 \\
$\mathrm{CP}\left(\mathrm{mg} \mathrm{g}^{-1} \mathrm{DM}\right)$ & 364.0 & 364.1 & 359.5 & 383.3 & 374.5 & 2.73 & $\mathrm{~ns}$ \\
Fat $\left(\mathrm{mg} \mathrm{g}^{-1} \mathrm{DM}\right)$ & 417.1 & 415.1 & 418.7 & 405.5 & 417.3 & 1.99 & $\mathrm{~ns}$ \\
TBARS $(\mu \mathrm{M})$ & 2.15 & 2.34 & 2.29 & 2.21 & 2.23 & 0.11 & $\mathrm{~ns}$ \\
\hline
\end{tabular}

${ }^{a}$ Values are means (number of samples for each treatment at any time $=3$ ); means with different superscript letters within a row are significantly different $(P<0.05)$. Abbreviations are: SEM, standard error of the means; $P$, probability of significant effect due to the treatment (ns, not significant); $\mathrm{C} 1$, control 1 (no treatment); $\mathrm{C} 2$, control 2 (treated with a commercial polymeric solution containing silver ion); LCHE200 and LCHE400, cheeses treated with the solution of chestnut tannin extract at $200 \mathrm{~g} \mathrm{~L}^{-1}$ and $400 \mathrm{~g} \mathrm{~L}^{-1}$, respectively; LCHEP, cheese loaves treated with chestnut tannin extract powder, DM, dry matter; $\mathrm{CP}$, crude protein; TBARS, thiobarbituric acid reactive substances. 
shows that this species is able to grow on tannins (Aguilar \& Gutierrez-Sanchez, 2001; Lekha \& Lonsane, 1997).

CHE 400 and CHEP were effective in inhibiting the proliferation of this mould within 15 days and in decreasing it in the last 20 days of ageing. However, the proliferation of $P$. commune on cheeses represents less serious aesthetic damage than that of C. cladosporioides because the mycelium of this species can be easily removed from the surface of the cheeses by brushing before marketing.

P. commune, in fact, frequently contaminates foods and it was found on several cheeses such as Cheddar and on Italian goats' and sheep's milk cheeses (Hayaloglu \& Kirbag, 2007; Hocking \& Faedo, 1992; Kure et al., 2001; Montagna et al., 2004). This microorganism is considered as the wild type ancestor of $P$. camemberti and is able to grow in the air with high levels of carbon dioxide as that of longripening cheese chambers (Kure \& Skaar, 2000). Several studies indicated that the probability of detecting this mould follows a seasonal fluctuation, but the reason of this behaviour is not obvious (Kure et al., 2004; Ren, Jankun, \& Leaderer, 1999). Air and cheese making equipment through the entire production line represent crucial points for potential contamination.

It should be noted that, even if in the literature there is no current evidence for human toxicity reported, $P$. commune could be potentially harmful for consumers because it is able to produce cyclopiazonic acid, a mycotoxin able to inhibit the $\mathrm{Ca}^{2+}$-ATPase in intracellular $\mathrm{Ca}^{2+}$ storage sites (Cousin, 2003; Sosa et al., 2002).

The impact of most non-starter moulds and yeasts in cheeses is not completely known and the literature suggests that this microbiota could induce a contribution to the flavour and texture in cheeses (Fleet, 1990; Pereira-Diaz, Potes, Marinho, MalfeitoFerreira, \& Loureiro, 2000). CHE and silver ion solutions used in this trial did not completely inhibit mould and yeast proliferation, but their growth was affected by the kind of solution and its molarity. However, the trend of microbial growth is very low. The presence of high numbers of $P$. commune on the samples treated with silver ion solution is not easily explained because of its high ability in inhibiting the microbial colonisation in foods. It is possible that the continuous use of this antimicrobial could have selected for Penicillium strains with high resistance to the silver ion polymer used. However, a lag-time for the antimicrobial activities of polyphenols and ion solution against $P$. commune, within day 80 , could be considered. Moreover, the tannin concentration used for the solution LCHE200 was not efficient in avoiding microbial contamination by this microorganism, with a similar trend to the untreated cheeses (C1). In contrast, silver ion (C2) and the tannin treatments (LCHE400 and LCHEP) seem to be efficient after 80 days from cheese making, decreasing the concentration of moulds compared with that on untreated cheeses or cheeses treated at up to $200 \mathrm{~g} \mathrm{~L}^{-1}$.

When the silver ion solution was used, yeast proliferation was stable for the whole period of ripening with the exception of the sampling at day 40, maybe due of the intrinsic variability of samples. With CHE200, the growth of yeasts increased constantly even if the initial values were lower than that of the other cheese units and the final values were comparable with those of C2. CHE400 and CHEP showed yeast growth only at 80 days, but this growth was very low.

In this trial, also a yeast static effect of CHE was observed during the first period of ripening (within 40 days). Usually, the cheese is contaminated by an environment rich in yeasts when it is plunged in the brine. In particular, $D$. hansenii is resistant to the salt solution (Butinar, Santos, Spencer-Martins, Oren, \& GundeCimerman, 2005; Corte et al., 2006; Seiler \& Busse, 1990) even if its presence, however, on the crust should not be considered a problem. In fact, this species is an important component in the production of several cheese type made with ewes' milk (Cosentino, Fadda, Deplano, Mulargia, \& Palmas, 2001; Del Bove et al., 2009; Fadda, Mossa, Pisano, Deplano, \& Cosentino, 2004; Gardini et al., 2006). D. hansenii can contribute to the development of the flavour, exerting important metabolic activities during ripening and limiting the growth of deleterious spoiling bacteria (Bonaiti, Leclercq-Perlat, Latrille, \& Corrieu, 2004; Cousin, 2003; Fatichenti, Bergere, Deiana, \& Farris, 1983). However, before marketing, its cells can be easily removed from the surface of the cheese by washing or brushing. Compared with the case for moulds, for yeasts the tannin treatments were effective at each point of sampling with the exception of day 40 according to a lagtime of efficiency. However, the mechanism of tannin action on microorganisms is not clear. The action could direct in various ways such as breaking of cell membrane linking proteins, inhibition of enzymes, ion deprivation; however, for hydrolysable polyphenols, it can be hypothesised that there is also indirect action by derivatives formed after initial microbial metabolism (Espin et al., 2007; Patra \& Saxena, 2011).

\section{Conclusion}

The results of the present study indicated that CHE is capable of inhibiting $C$. cladosporioides proliferation during the ripening of semi-hard sheep cheese. The efficacy of CHE solutions to avoid the cheese spoilage started from a concentration of $200 \mathrm{~g} \mathrm{~L}^{-1}$ and this concentration can be suggested as practical dose in cheese making procedure. An additional benefit of using a natural antimicrobial is the replacement of antibiotics or of synthetic chemical solutions whose use leads to problem of microbial resistance, of the environmental pollution, of food sanity for consumers, and of wastewater disposal.

\section{Acknowledgements}

This work was supported by the Agricultural Department or Regione Toscana - Italy (PROINNOVA Project-PROGRAMMA DI SVILUPPO RURALE (PSR) 2007-2013 - Reg. CE n. 1698/2005 GAL), and by Nuovo Gruppo Mauro Saviola, Mantova Italy.

\section{References}

Aguilar, N. C., \& Gutierrez-Sanchez, G. (2001). Review: Sources, properties, applications and potential uses of tannin acyl hydrolase. Food Science and Technology International, 7, 373-382.

Altschul, S. F., Gish, W., Miller, W., Myers, E. W., \& Lipman, D. J. (1990). Basic local alignment search tool. Journal of Molecular Biology, 215, 403-410.

AOAC. (1995). Official methods of analysis of the AOAC International (15th ed.). Arlington, VA, USA: AOAC International.

Bauer, A. W., Kirby, W. M., Sherris, J. C., \& Turck, M. (1966). Antibiotic susceptibility testing by a standardized single disk method. American Journal of Clinical Pathology, 45, 493-496.

Bonaiti, C., Leclercq-Perlat, M. N., Latrille, E., \& Corrieu, G. (2004). Deacidification by Debaryomyces hansenii of smear soft cheeses ripened under controlled conditions: Relative humidity and temperature influences. Journal of Dairy Science, 87, 3976-3988.

Buccioni, A., Minieri, S., Conte, G., Benvenuti, D., Pezzati, A., Antongiovanni, M., et al. (2012). Changes in conjugated linoleic acid and C18:1 isomers profile during the ripening of Pecorino Toscano cheese produced with raw milk. Italian Journal of Animal Science, 11, e75

Buccioni, A., Rapaccini, S., Antongiovanni, M., Minieri, S., Conte, G., \& Mele, M. (2010). Conjugated linoleic acid (CLA) and C18:1 isomers content in milk fat of sheep and their transfer to Pecorino Toscano D.O.P. cheese. International Dairy Journal, 20, 190-194.

Burns, R. E. (1963). Methods of tannin analysis for forage crop evaluation. Technical Bullettin number 32. Athens, GA, USA: Georgia Agricultural Experiment Station.

Butinar, L., Santos, S., Spencer-Martins, I., Oren, A., \& Gunde-Cimerman, N. (2005). Yeast diversity in hypersaline habitats. FEMS Microbiology, 51, 121-130.

Campo, M., Pinelli, P., \& Romani, A. (2012). HPLC/DAD/MS characterization and antioxidant activity of sweet chestnut (Castanea sativa M.) fractions. In Proceedings of the XXVI International Conference on Polyphenols (pp. 135-136). Florence, Italy: ICP. 
Corte, L., Rellini, P., Lattanzi, M., Picchetta, C., Fatichenti, F., \& Cardinali, G. (2006). Diversity of salt response among yeasts. Annals of Microbiology, 56, 363-368.

Cosentino, S., Fadda, M. E., Deplano, M., Mulargia, A. F., \& Palmas, F. (2001). Yeasts associated with Sardinian ewe's dairy products. International Journal of Food Microbiology, 69, 53-58.

Cousin, M. A. (2003). Moulds in dairy products. In H. Roginski, J. W. Fuquay, \& P. F. Fox (Eds.), Encyclopedia of dairy sciences (pp. 2072-2078). New York, NY, USA: Academic Press.

Del Bove, M., Lattanzi, M., Rellini, P., Pelliccia, C., Fatichenti, F., \& Cardinali, G. (2009), Comparison of molecular and metabolomic methods as characterization tools of Debaryomyces hansenii cheese isolates. Food Microbiology, 26, 453-459.

Delavenne, E., Mounier, J., Asmani, K., Jany, J. L., Barbier, G., \& Le Blay, G. (2011). Fungal diversity in cow, goat and ewe milk. International Journal of Food Microbiology, 151, 247-251.

Espin, J. C. Gonzalez-Barrio, R., Cerda, B., Lopez-Bote, C., Rey, A. I., \& TomasBarberan, F. A. (2007). Iberian pig as model to clarify obscure points in the bioavailability and metabolism of ellagitannins in humans. Journal of Agricultural Food Chemistry, 55, 10476-10485.

Esteve-Zarzoso, B., Belloch, C., Uruburu, F., \& Querol, A. (1999). Identification of yeasts by RFLP analysis of the 5.8 rRNA gene and the two ribosomal internal transcribed spacers. International Journal of Systematic Bacteriology, 49, 329-337.

Fadda, M. E., Mossa, V., Pisano, M. B., Deplano, M., \& Cosentino, S. (2004). Occurrence and characterization of yeasts isolated from artisanal Fiore Sardo cheese. International Journal of Food Microbiology, 95, 51-59.

Fatichenti, F., Bergere, J. L., Deiana, P., \& Farris, G. A. (1983). Antagonistic activity of Debaryomyces hansenii towards Clostridium tyrobutyricum and $\mathrm{Cl}$. butyricum. Journal Dairy Research, 50, 449-457.

Fleet, G. H. (1990). Yeasts in dairy products. Journal Applied Microbiology, 68, $199-211$.

Galli Volonterio, A. (2005). Food microbiology (pp. 184-185). Milano, IT: Casa Editrice Ambrosiana.

Gardini, F., Tofalo, R., Belletti, N., Iucci, L., Suzzi, G., Torriani, S., et al. (2006). Characterization of yeasts involved in the ripening of Pecorino Crotonese cheese. Food Microbiology, 23, 641-648.

Granchi, L., Bosco, M. Messini, A., \& Vincenzini, M. (1999). Rapid detection and quantification of yeast species during spontaneous wine fermentation by PCRRFLP analysis of the rDNA ITS region. Journal of Applied Microbiology, 87, 949-956.

Gripon, J. C. (1993). Mould ripened cheeses. In P. F. Fox (Ed.), Cheese: Chemistry, physics and microbiology (pp. 111-136). London, UK: Chapman \& Hall.

Havaux, X., Zeine, A., Dits, A., \& Denis, O. (2005). A new mouse model of lung allergy induced by the spores of Alternaria alternata and Cladosporium herbarum molds. Clinical and Experimental Immunology, 139, 179-188.

Hayaloglu, A. A., \& Kirbag, S. (2007). Microbial quality and presence of moulds in Kuflu cheese. International Journal of Food Microbiology, 115, 376-380.

Hocking, A. D., \& Faedo, M. (1992). Fungi causing thread mould spoilage of vacuum packaged Cheddar cheese during maturation. International Journal of Food Microbiology, 16, 123-130.

ISO/IDF. (1975). Cheese. Determination of fat content. Van Gulik method. ISO standard 3433. Geneva, Switzerland: International Organization for Standardization.

Knutsen, A. P., Bush, R. K., Demain, J. G., Denning, D. W., Dixit, A., Fairs, A., et al. (2012). Fungi and allergic lower respiratory tract diseases. Journal of Allergy and Clinical Immunology, 129, 280-291.

Kure, C. F., \& Skaar, I. (2000). Mould growth on the Norwegian semi-hard cheeses Norvegia and Jarlsberg. International Journal of Food Microbiology, 62, 133-137.

Kure, C. F., Skaar, I., \& Brendehaug, J. (2004). Mould contamination in production of semi-hard cheese. International Journal of Food Microbiology, 93, 41-49.

Kure, C. F., Wasteson, Y., Brendehaug, J., \& Skaar, I. (2001). Mould contaminants on Jarlsberg and Norvegia cheese blocks from four factories. International Journal of Food Microbiology, 70, 21-27.

Landete, J. M. (2011). Ellagitannins, ellagic acid and their derived metabolites: A review about source, metabolism, functions and health. Food Research International, 44,1150-1160.
Lekha, P. K., \& Lonsane, B. K. (1997). Production and application of tannin acyl hydrolase: State of the art. Advances in Applied Microbiology, 44, 215-260.

Machado, I., Lozano, T. M., Bañón, J. L. J., Mojarrieta, J. C., \& Estevan, R. (2012). Granulomatosis intraabdominal por Cladosporium cladosporioides. Revista Española de Patología, 45, 40-44.

Montagna, M. T., Santacroce, M. P., Spilotros, G., Napoli, C., Minervini, F., Papa, A. et al. (2004). Investigation on fungal contamination in sheep and goat cheeses in sourthern Italy. Mycopathologia, 158, 245-249.

Obreque-Slíer, E., Peña-Neira, A., López-Solís, R., Ramírez-Escudero, C., \& ZamoraMarín, F. (2009). Phenolic characterization of commercial enological tannins. European Food Research and Technology, 229, 859-866.

Okuda, T. (2005). Systematics and health effects of chemically distinct tannins in medicinal plants. Phytochemistry, 66, 2012-2031.

Patra, A. K., \& Saxena, J. (2011). Exploitation of dietary tannins to improve rumen metabolism and ruminant nutrition. Journal of the Science of Food and Agriculture, 91, 24-37.

Patton, S., \& Kruiz, G. W. (1951). 2-Thiobarbituric acid as reagent for detecting milk fat oxidation. Journal of Dairy Science, 34, 669-674.

Pereira-Diaz, S., Potes, M. E., Marinho, A., Malfeito-Ferreira, M., \& Loureiro, V (2000). Characterization of yeast flora isolated from artisanal Portuguese ewes' cheese. International Journal of Food Microbiology, 60, 55-63.

Pulvirenti, A., Solieri, L., Gullo, M., De Vero, L., \& Giudici, P. (2004). Occurrence and dominance of yeast species in sourdough. Letters in Applied Microbiology, 38 $113-117$.

Ren, P., Jankun, T. M., \& Leaderer, B. P. (1999). Comparisons of seasonal fungal prevalence in indoor and outdoor air and in house dusts of dwellings in one Northeast American county. Journal of Exposure Analysis and Environmental Epidemiology, 9, 560-568.

Romani, A., Campo, M., \& Pinelli, P. (2013). HPLC/DAD/ESI-MS analyses and antiradical activity of hydrolyzable tannins from different vegetal species. Food Chemistry, 130, 214-221.

SAS.. (1999). User's guide: Statistics. Version 8.0. Cary, NC, USA: SAS Institute Inc.

Seiler, H., \& Busse, M. (1990). The yeasts of cheese brines. International Journal of Food Microbiology, 11, 289-303.

Sharpe, R. A., Bearman, N., Thornton, C. R., Husk, K., \& Osborne, N. J. (2015). Indoor fungal diversity and asthma: A meta-analysis and systematic review of risk factors. Journal of Allergy and Clinical Immunology, 135, 110-122.

Sørhaug, T. (2011). Spoilage molds in dairy products. In H. Roginski, J. W. Fuquay, \& P. F. Fox (Eds.), Encyclopedia of dairy sciences (pp. 780-784). New York, NY, USA: Academic Press.

Sosa, M. J., Córdoba, J. J., Díaz, C., Rodríguez, M., Bermúdez, E., Asensio, M. A., et al (2002). Production of cyclopiazonic acid by Penicillium commune isolated from dry-cured ham on a meat extract-based substrate. Journal of Food Protection, 65 988-992.

Tosi, G., Massi, P., Antongiovanni, M., Buccioni, A., Minieri, S., Marenchino, L., et al. (2013). Efficacy test of a hydrolysable tannin extract against necrotic enteritis in challenged broiler chickens. Italian Journal of Animal Science, 12, 386-389.

Vaughan, A., Buzzini, P., \& Clementi, F. (2008). Educational lab of microbiology (pp. 89-91). Milano, Italy: Casa Editrice Ambrosiana.

Venturi, M., Guerrini, S., \& Vincenzini, M. (2012). Stable and non-competitive association of Saccaromyces cerevisiae, Candida milleri and Lactobacillus sanfranciscensis during manufacture of two traditional sourdough baked goods. Food Microbiology, 31, 107-115.

White, T. J., Bruns, T., Lee, S., \& Taylor, J. (1990). Amplification and direct sequencing of fungal ribosomal RNA genes for phylogenetics. In M. A. Innis, D. H. Gelfand, J. J. Sninsky, \& T. J. White (Eds.), PCR protocols: A guide to methods and applications (pp. 315-322). London, UK: Academic Press.

Wistreich, G. A. (1997). Microbiology laboratory. Fundamentals and applications ( $p p$. 46-53. Upper Saddle River, NJ, USA: Prentice Hall.

Zeng, Q. Y., Westermark, S. O., RasmusonLestander, A., \& Wang, X. R. (2006). Detection and quantification of Cladosporium in aerosols by real-time PCR Journal of Environmental Monitoring, 8, 153-160.

Zottola, E. A., \& Smith, L. B. (1993). Growth and survival of undesirable bacteria in cheese. In P. F. Fox (Ed.), Cheese: Chemistry, physics and microbiology (pp. 471-492). London, UK: Chapman \& Hall. 